\title{
Maintenance Scenario of Concrete Structures Damaged by Reinforcement Corrosion Based on Corrosion Propagation Mechanism of Steel and Moisture Behavior in Concrete
}

\author{
Satoshi Takaya ${ }^{1 *}$, Ryosuke Saito ${ }^{2}$, Shinichi Satoh ${ }^{3}$ and Takashi Yamamoto ${ }^{4}$
}

Received 01 February 2021, accepted 11 May 2021

doi:10.3151/jact.19.614

\begin{abstract}
It can be said that corrosion of reinforcing steel is a serious problem for concrete structures. However, the corrosion mechanism of steel is still unclear, and it is difficult to prevent corrosion perfectly. In this study, in order to make clear the corrosion process in alkaline environment, the corrosion products formed in solutions of various $\mathrm{OH}^{-}$and $\mathrm{Cl}^{-}$concentrations were evaluated by Raman spectroscopy. In addition, the influence of dissolved oxygen on corrosion products was investigated. Furthermore, the corrosion mechanism of steel in concrete was investigated based on field study. These investigations made it clear that the behavior of moisture in concrete has large influence on corrosion propagation. Therefore, the influence of $\mathrm{W} / \mathrm{C}$, chloride ions and cracks on the behavior of moisture in concrete was also investigated. Based on the the results obtained, the authors propose a maintenance scenario for concrete structures damaged by corrosion of the reinforcement.
\end{abstract}

\section{Introduction}

Reinforcing steel in concrete is protected from corrosion because the $\mathrm{pH}$ in concrete is 12 to 13 . However, the reinforcement begins to corrode under conditions of chloride ion existing around the reinforcing steel or dropping of $\mathrm{pH}$ due to carbonation. When reinforcement corrodes, cracks are induced in cover concrete because the volume of corrosion products is much larger than that of the original steel. Factors of deterioration such as water, oxygen or chloride ions that penetrate through these cracks accelerate corrosion, and the consequent corrosion of steel may cause reductions in the load-carrying capacity of concrete structures. Because Japan is surrounded by the sea, and also has many mountainous areas where deicing salt is used in winter, reinforcement corrosion is a serious problem for concrete structures. Therefore, it is important to protect concrete structures from corrosion. However, the corrosion mechanism of steel is still unclear, and it is difficult to prevent corrosion perfectly.

It is well known that corrosion rate is largely influenced by environment. It has been reported in previous

\footnotetext{
${ }^{1}$ Assistant Professor, Kyoto University, C1-220 Kyotodaigaku-katsura, Nishikyo-ku, Kyoto, Japan.

*Corresponding author,

E-mail: takaya.satoshi.4n@kyoto-u.ac.jp

${ }^{2}$ Researcher, Shimizu Corporation, 3-4-17 Etchujima, Koto-ku, Tokyo, Japan.

${ }^{3}$ Chief Senior Research Scientist, Osaka Research Institute of Industrial Science and Technology, 2-7-1 Ayumino Izumi, Osaka, Japan.

${ }^{4}$ Professor, Kyoto University, C1-455 Kyotodaigaku-katsura, Nishikyo-ku, Kyoto, Japan.
}

studies that the corrosion products formed also differ depending on the environment (Takaya et al. 2013; Nishizawa et al. 2013). Therefore, it can be thought that the corrosion propagation mechanism could be made clear by clarifying the process of formation of corrosion products.

In this study, in order to make clear the process of corrosion in alkaline environment, corrosion testing of steel plates in a variety of hydroxide ion $\left(\mathrm{OH}^{-}\right)$and chloride ion $\left(\mathrm{Cl}^{-}\right)$environments was carried out first, and the resulting corrosion products were analyzed by means of Raman spectroscopy. This was followed by investigation of the influence of dissolved oxygen on formation of corrosion products. Furthermore, the corrosion environments in actual structures and the resulting corrosion products were investigated through field studies, and finally, the corrosion propagation process of steel in concrete was considered.

The results of these investigations made it clear that the behavior of moisture in concrete has large influence on corrosion propagation. Consequently, the influence of $\mathrm{W} / \mathrm{C}, \mathrm{Cl}^{-}$and cracks on the behavior of moisture in concrete was also investigated. Based on the results obtained, the authors propose a maintenance scenario of concrete structures damaged by reinforcement corrosion.

This paper is an extended and enhanced version of an earlier work [Takaya, S., Satoh, S., Hamura, Y., Yamamato, T. and Miyagawa, T., (2020). "Corrosion mechanism of steel in concrete." In: Proceedings of ConMat'20, The 6th International Conference on Concrete Materials Performance, Innovations, and Structural Implications, Fukuoka, Japan 27-29 August 2020. Tokyo: Japan Concrete Institute, Paper No. 7-4_14.] 


\section{Passive film formed in alkaline environment}

\subsection{Purpose}

Though there are various theories concerning the composition of passive films on iron, these films are generally considered to be $\gamma-\mathrm{Fe}_{2} \mathrm{O}_{3}$ or $\gamma-\mathrm{Fe}_{2} \mathrm{O}_{3} / \mathrm{Fe}_{3} \mathrm{O}_{4}$ composites (Nieuwoudt et al. 2012). It is often said that steel in concrete is protected from corrosion by the passive films formed on its surface because in concrete is a highly alkaline environment. However, studies on passive film formed in alkaline environments are few and many points still remain unclear. Therefore, the first investigation made in this study was a comparison of the composition of passive films formed in acidic and alkaline solutions.

\subsection{Experimental details}

The samples were $10 \times 10 \times 1.5 \mathrm{~mm}$ sized steel plates (SS400), with their surfaces polished using \#150 to \#1200 abrasive papers progressively after being degreased with acetone and ethanol. The samples were immersed for two weeks in $60 \mathrm{wt} \%$ solution of nitric acid $\left(\mathrm{HNO}_{3}\right)$ and $0.1 \mathrm{~mol} / \mathrm{L}$ solution of sodium hydroxide $(\mathrm{NaOH})$ in covered Petri dishes kept indoors at $20^{\circ} \mathrm{C}$. The oxide film that formed on their surfaces was ana- lyzed by x-ray photoelectron spectroscopy (XPS). In this experiment, sputtering (surface etching) was not conducted to avoid reduction of the oxide films.

\subsection{Results and discussion}

Figure 1 shows the appearance of the steel surfaces after immersion. From the figure it is confirmed that samples were kept passivated and were not corroded.

The results of XPS analysis carried out for passive films are shown in Fig. 2. Although the attributes of the peaks are also shown in the figure, attention is needed because differences in the method of calibration method cause slight differences in the peaks. In this study, hydrocarbon was used as the energy reference for the spectra, and the energy axis was calibrated based on $\mathrm{C} 1 \mathrm{~s}=285.0 \mathrm{eV}$.

The appearance of a $\mathrm{Fe} 2 \mathrm{p} 3 / 2\left(\mathrm{Fe}_{2} \mathrm{O}_{3}\right)$ peak near 710 $\mathrm{eV}$ and a trivalent satellite peak near $720 \mathrm{eV}$ in the case of the steel immersed in $\mathrm{HNO}_{3}$ suggest that the passive film formed in acid environment consists of $\mathrm{Fe}_{2} \mathrm{O}_{3}$, which seems to be $\gamma$-phase from the description of Nieuwoudt et al. (2012). On the other hand, the spectra for the sample that was immersed in $\mathrm{NaOH}$ reveals that the peaks have shifted slightly to the right compared to the sample that was immersed in $\mathrm{HNO}_{3}$. Though the

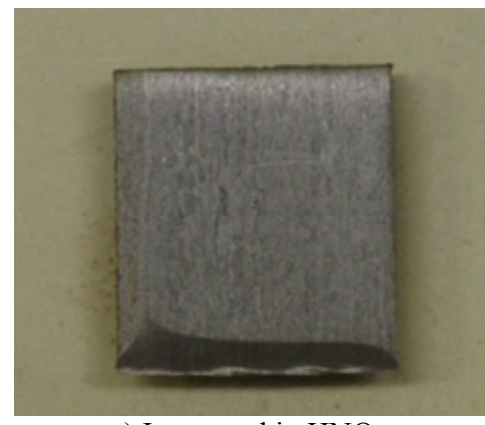

a) Immersed in $\mathrm{HNO}_{3}$

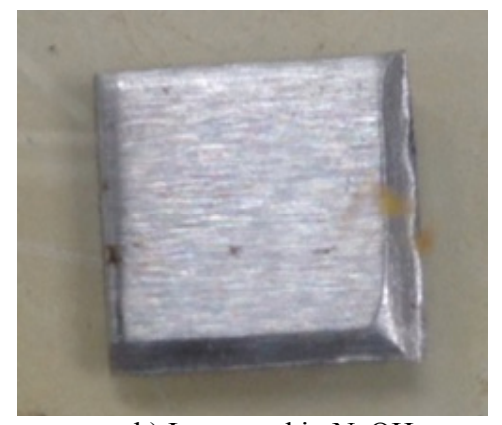

b) Immersed in $\mathrm{NaOH}$

Fig. 1 Appearances after 2 weeks immersion.

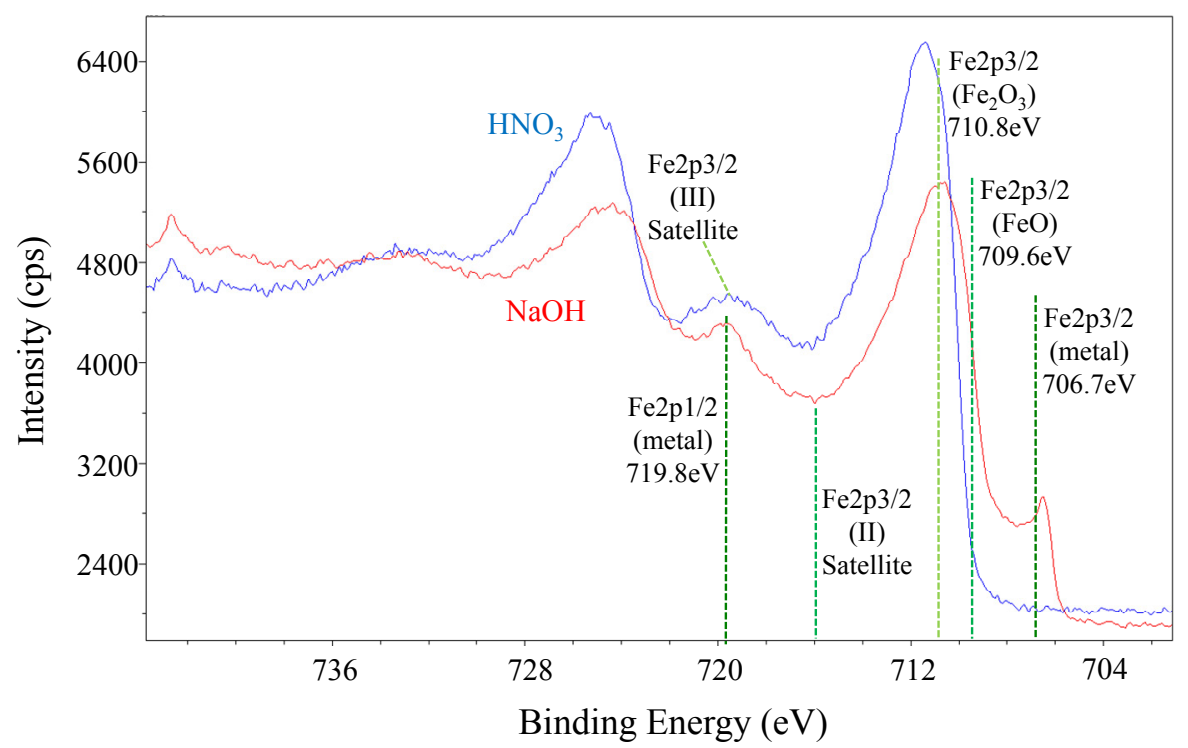

Fig. 2 Results of XPS analysis of passive film. 
Table 1 Measured $\mathrm{pH}$ of each testing condition.

\begin{tabular}{|c|c|c|c|}
\hline & $\mathrm{Cl}^{-} / \mathrm{OH}^{-}=0$ & $\mathrm{Cl}^{-} / \mathrm{OH}^{-}=0.75$ & $\mathrm{Cl}^{-} / \mathrm{OH}^{-}=1.5$ \\
\hline $\mathrm{pH}=13$ & 13.0 & 13.0 & 13.0 \\
\hline $\mathrm{pH}=11$ & 11.2 & 11.2 & 11.2 \\
\hline $\mathrm{pH}=9$ & 9.3 & 9.2 & 9.1 \\
\hline
\end{tabular}

obtained spectrum is close to $\mathrm{FeO}$, the bivalent satellite peak that appears near $716 \mathrm{eV}$ was not observed. Considering the results of Raman spectroscopy, which are described in the next chapter, it is thought that the passive film that formed in alkaline environment consists of $\mathrm{Fe}_{3} \mathrm{O}_{4}\left(\mathrm{Fe}_{2} \mathrm{O}_{3} / \mathrm{FeO}\right)$. In the case of $\mathrm{Fe}_{3} \mathrm{O}_{4}$, a combined spectrum of $\mathrm{Fe}_{2} \mathrm{O}_{3}$ and $\mathrm{FeO}$ is obtained. This makes it difficult to separate each satellite peak clearly because the bivalent and trivalent satellite peaks overlap. Though the peak near $720 \mathrm{eV}$ is observed in the spectrum of the sample immersed in $\mathrm{NaOH}$, it can be thought that this peak attributes to $\mathrm{Fe} 2 \mathrm{p} 1 / 2$ (metal) because the Fe2p3/2 (metal) peak at $706.7 \mathrm{eV}$ is also observed.

To summarize, $\gamma-\mathrm{Fe}_{2} \mathrm{O}_{3}$ is formed as a passive film in acid environment, whereas $\mathrm{Fe}_{3} \mathrm{O}_{4}$ is formed as a passive film in alkaline environment.

\section{Influence of $\mathrm{OH}^{-}$and $\mathrm{Cl}^{-}$on corrosion products}

\subsection{Purpose}

From the results of the previous section, it was confirmed that steel is prevented from corrosion by the passive $\mathrm{Fe}_{3} \mathrm{O}_{4}$ film in highly alkaline environments. However, it is known that corrosion occurs even in the highly alkaline environment of concrete if the $\mathrm{pH}$ drops due to carbonation or if chloride ions exist. This fact implies that hydroxide ions $\left(\mathrm{OH}^{-}\right)$and chloride ions $\left(\mathrm{Cl}^{-}\right)$have a large influence on corrosion products. Therefore, in order to make clear the influence of $\mathrm{OH}^{-}$and $\mathrm{Cl}^{-}$on corrosion products, corrosion testing of steel was carried out at a variety of $\mathrm{pH}$ levels and $\mathrm{Cl}^{-} / \mathrm{OH}^{-}$molar ratios in order to compare the compositions of the resulting corrosion products by Raman spectroscopy.

\subsection{Experimental details}

The samples were $10 \times 10 \times 1.5 \mathrm{~mm}$ sized steel plates (SS400), with their surfaces polished using \#150 to \#1200 abrasive papers progressively after degreasing with acetone and ethanol. One sample was prepared for each combination of the following experimental factors: $\mathrm{pH}$ (three values: 13, 11 and 9) and $\mathrm{Cl}^{-} / \mathrm{OH}^{-}$molar ratio (three ratios: $0,0.75$, and 1.5$)$. $\mathrm{NaOH}$ was used for control of the $\mathrm{pH}$, and $\mathrm{NaCl}$ was used for control of the $\mathrm{Cl}^{-}$concentration. The experimental factors and the measured $\mathrm{pH}$ levels prior to the corrosion test are listed in Table $\mathbf{1}$.

The samples were immersed in solutions that had been controlled to the conditions listed above, and the corrosion products formed were analyzed by means of Raman spectroscopy after they had been immersed for 30 days. Analysis was carried out as the samples were immersed in the solutions. A $532 \mathrm{~nm}$ wavelength laser, which is well suited to the analysis of metallic compounds, was used for the incident light. It should be added that the corrosion test was carried out in covered Petri dishes kept in a $25^{\circ} \mathrm{C}$ thermostatic bath.

\subsection{Results and discussion}

Formation of corrosion products was observed on the surface of all samples except the one immersed in the $\mathrm{pH}=13$ and $\mathrm{Cl}^{-} / \mathrm{OH}^{-}=0$ solution within two or three days after the start of the corrosion test. The appearances of the sample surfaces after the corrosion test are shown in Fig. 3. In the case of the $\mathrm{pH}=13, \mathrm{Cl}^{-} / \mathrm{OH}^{-}=0$ sample,

\begin{tabular}{|l|l|l|l|}
\hline $\mathrm{Cl} / \mathrm{OH}=0$ & $\mathrm{Cl} / \mathrm{OH}=0.75$ & $\mathrm{Cl} / \mathrm{OH}=1.5$ \\
\hline $\mathrm{pH}=13$ & & & \\
\hline $\mathrm{pH}=11$ & & & \\
\hline
\end{tabular}

Fig. 3 Appearances of each sample after corrosion test. 
Table 2 Results of semi-quantitative analysis.

\begin{tabular}{|c|c|c|c|c|}
\hline & & $\mathrm{Cl}^{-} / \mathrm{OH}^{-}=0$ & $\mathrm{Cl}^{-} / \mathrm{OH}^{-}=0.75$ & $\mathrm{Cl}^{-} / \mathrm{OH}^{-}=1.5$ \\
\hline \multirow{2}{*}{$\mathrm{pH}=13$} & $\mathrm{Fe}_{3} \mathrm{O}_{4}$ & $99.6 \%$ & $99.9 \%$ & $99.7 \%$ \\
\hline & $\gamma$-FeOOH & $0.4 \%$ & $0.1 \%$ & $0.3 \%$ \\
\hline \multirow{2}{*}{$\mathrm{pH}=11$} & $\mathrm{Fe}_{3} \mathrm{O}_{4}$ & $53.0 \%$ & $28.3 \%$ & $1.8 \%$ \\
\hline & $\gamma$-FeOOH & $47.0 \%$ & $71.7 \%$ & $99.2 \%$ \\
\hline \multirow{2}{*}{$\mathrm{pH}=9$} & $\mathrm{Fe}_{3} \mathrm{O}_{4}$ & $7.2 \%$ & $6.2 \%$ & $6.9 \%$ \\
\hline & $\gamma$-FeOOH & $92.8 \%$ & $93.8 \%$ & $93.1 \%$ \\
\hline
\end{tabular}

corrosion products were not observed, and the formation of passive film was indicated. In the case of the $\mathrm{Cl}^{-} / \mathrm{OH}^{-}=0.75$ and 1.5 solutions at $\mathrm{pH}=13$, overall black-colored corrosion products can be observed on the samples, although the amounts of corrosion products were small. By contrast, overall reddish-brown corrosion products can be observed on the samples that were immersed in the $\mathrm{pH}=11$ and $\mathrm{pH}=9$ solutions regardless of $\mathrm{Cl}^{-} / \mathrm{OH}^{-}$molar ratio, and the amounts of corrosion products were large. The confirmed drops of $\mathrm{pH}$ in the solution were 0.2 to 0.5 overall after the corrosion test, and large changes in $\mathrm{pH}$ were not found. This may be because the effect of the carbon dioxide in the air was eliminated because the testing was in covered Petri dishes.

As examples of the Raman spectra obtained, the differences in spectra by $\mathrm{pH}$ level are shown in Fig. 4. Corrosion products other than $\mathrm{Fe}_{3} \mathrm{O}_{4}$ and $\gamma$-FeOOH were not detected in most cases. Although $\beta$-FeOOH was not detected, a previous report indicates that $\beta$-FeOOH only forms in environments in which $\mathrm{Cl}^{-}$exists at low $\mathrm{pH}$ levels (Jambor et al. 1998), suggesting that the result here was due to high $\mathrm{pH}$ levels.

Since it is difficult to discuss the results quantitatively with spectra only, semi-quantitative analysis was also conducted. The results are shown in Table 2. From the table, it can be said that as the $\mathrm{pH}$ level of the solution becomes lower or the $\mathrm{Cl}^{-} / \mathrm{OH}^{-}$molar ratio increases, the amount of $\mathrm{Fe}_{3} \mathrm{O}_{4}$ decreases, and instead, the amount of $\gamma$-FeOOH increases. In the case of the $\mathrm{pH}=13, \mathrm{Cl}^{-} / \mathrm{OH}^{-}=0$ solution, the peak of $\mathrm{Fe}_{3} \mathrm{O}_{4}$ was rather sharp compared to those of other samples, indicating fairly good crystallization. Therefore, whether $\mathrm{Fe}_{3} \mathrm{O}_{4}$ works as a passive film or as a corrosion product seems to depend on crystallinity.

Figure 5 shows the results of observation of the formation process of $\gamma$-FeOOH under the condition $\mathrm{pH}=9$ and $\mathrm{Cl}^{-} / \mathrm{OH}^{-}=1.5$, which is an environment in which $\gamma$-FeOOH forms easily. Though a large broad peak can be seen close to $1300 \mathrm{~cm}^{-1}$, this peak is omitted from this discussion because it is shared by multiple corrosion products, including $\gamma$-FeOOH and $\mathrm{Fe}_{3} \mathrm{O}_{4}$ (see Fig. 4). The peak was confirmed to be fluorescent, which is thought to be caused by structural defects of corrosion products. In the figure, the $\gamma$-FeOOH spectrum can be seen immediately after immersion (1 hour), and peaks attributable to intermediate products such as $\mathrm{Fe}(\mathrm{OH})_{2}$ and green rust (GR1) can be seen at 200 to $400 \mathrm{~cm}^{-1}$. GR 1 is an intermediate product formed under environments where $\mathrm{Cl}^{-}$exists. The peaks of $\mathrm{Fe}(\mathrm{OH})_{2}$ and $\mathrm{GR} 1$ decreased with time, and $\mathrm{Fe}_{3} \mathrm{O}_{4}$ formation was observed from 26.5 to 32.5 hours. After that, it was observed that the peak of $\mathrm{Fe}_{3} \mathrm{O}_{4}$ decreased eventually and that the peak of $\gamma$-FeOOH increased. Based on that fact, it can be thought that the surface of the steel became an oxygen-lacking environment temporarily during the $\gamma$-FeOOH

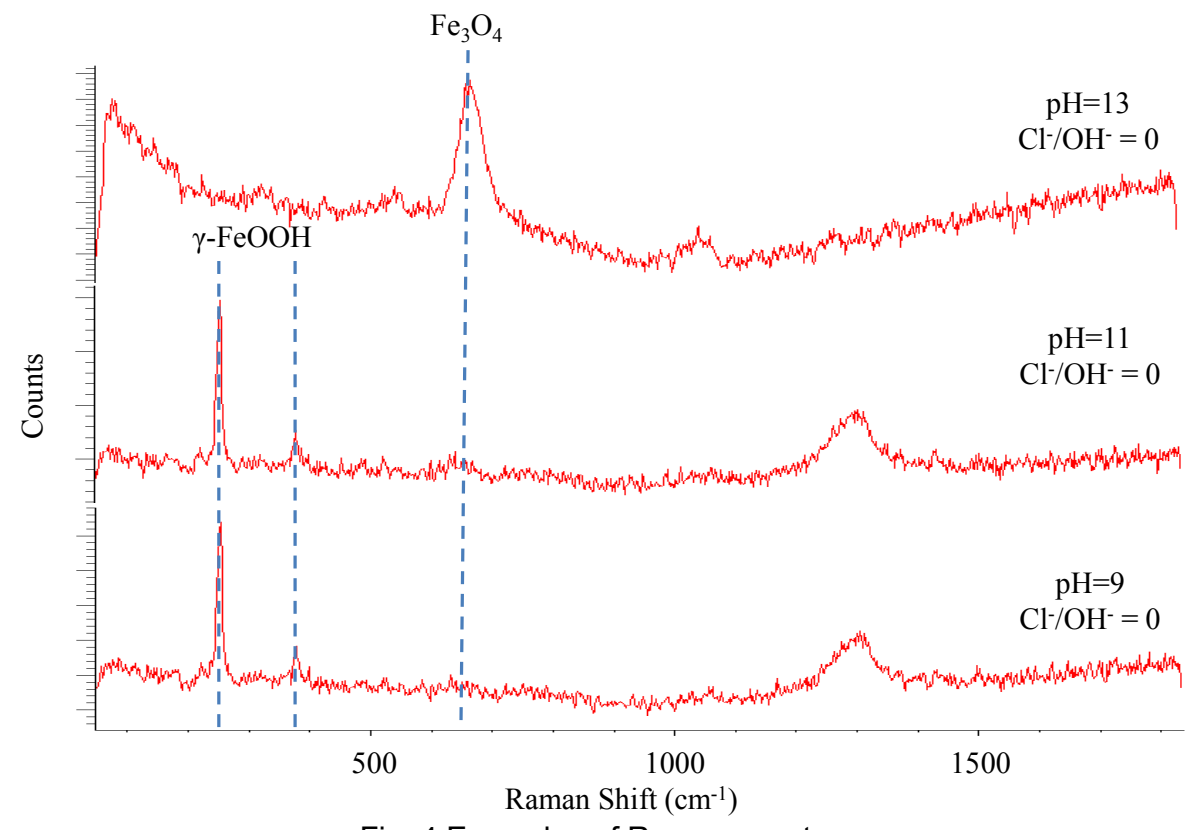

Fig. 4 Examples of Raman spectra. 
formation process, allowing $\mathrm{Fe}_{3} \mathrm{O}_{4}$ to form. This is because the amount of oxygen necessary for the formation of $\mathrm{Fe}_{3} \mathrm{O}_{4}$ is less than that of $\gamma$-FeOOH. However, because the crystallinity and stability of formed $\mathrm{Fe}_{3} \mathrm{O}_{4}$ were poor, $\mathrm{Fe}_{3} \mathrm{O}_{4}$ could change into $\gamma$-FeOOH by consuming oxygen supplied gradually by diffusion. That is to say, it can be said that not only $\mathrm{pH}$ and $\mathrm{Cl}^{-}$concentration but also dissolved oxygen is also important for corrosion products.

\section{Influence of dissolved oxygen on formation of corrosion products}

\subsection{Purpose}

In the investigation of the influence of $\mathrm{OH}^{-}$and $\mathrm{Cl}^{-}$on corrosion products as described in the previous section, it became clear that dissolved oxygen also has a large influence. While it is difficult to control the amount of dissolved oxygen, it has been reported that water films resist the diffusion of oxygen as the thickness of the films increases and that the change in relative humidity causes change in the thickness of such films (Tomashov 1964, 1966). Based on that information, it was attempted to carry out corrosion tests in desiccators in which the relative humidity could be controlled. The differences in the corrosion products were investigated with a view to clarify the influence of dissolved oxygen on corrosion products.

\subsection{Experimental details}

The samples were $10 \times 10 \times 1.5 \mathrm{~mm}$ sized steel plates (SS400) with their surfaces polished using \#150 to \#1200 abrasive papers progressively after degreasing with acetone and ethanol. A total of eight samples were prepared, one for each combination of the following experimental factors: relative humidity $(18 \%, 40 \%, 74 \%$, and 90\%) and $\mathrm{NaCl}$ concentration ( $3 \mathrm{wt} \%$ and $0.005 \mathrm{wt} \%$ ). A glycerin solution was used to control relative humidity.
The test was conducted as described below. First, $150 \mu \mathrm{L}$ of salt water that had been controlled to the concentrations described above was dropped onto the surface of the steel samples, which were then dried for 41 hours at room temperature inside a desiccator in which silica gel had been placed. Then each sample was corroded for 14 days in desiccators containing a glycerin solution controlled to the predetermined concentrations. The temperature in the desiccators was kept at $23^{\circ} \mathrm{C}$ during the corrosion test, and the corrosion products on the surface of the samples were compared.

\subsection{Results and discussion}

The relative humidities measured inside the desiccator during the corrosion test are shown in Fig 6. Although the measurements for the $90 \% \mathrm{RH}$ desiccator are slightly lower than the target value, the other measurements indicate that the humidity was generally kept at the target values. The large fluctuation in humidity near $2000 \mathrm{~min}$ was a point of time the corrosion test started, and the humidity inside the desiccator is seen to approach the room humidity $(50 \% \mathrm{RH})$ when the cover of desiccator was opened.

Figure 7 shows the appearance of the corrosion products formed. Although the $18 \% \mathrm{RH}$ and $40 \% \mathrm{RH}$ samples for $3 \mathrm{wt} \% \mathrm{NaCl}$ were covered overall by red-colored rust that is likely to be $\gamma-\mathrm{FeOOH}$, a large amount of black rust that is likely to be $\mathrm{Fe}_{3} \mathrm{O}_{4}$ can be seen in case of the higher-humidity $74 \% \mathrm{RH}$ and $90 \% \mathrm{RH}$ samples. This difference suggests that the thickness of water film increased as relative humidity became higher, causing the film to resist oxygen diffusion. For the 0.005 $\mathrm{wt} \% \mathrm{NaCl}$ samples, on the other hand, red rust that is likely to be $\gamma$-FeOOH can be seen on all samples, regardless of the relative humidity. The extent of corrosion overall is lower compared to $3 \mathrm{wt} \% \mathrm{NaCl}$, and this change is inferred to derive from the fact that oxygen diffusion was not limited, which was due to the low $\mathrm{Cl}^{-}$

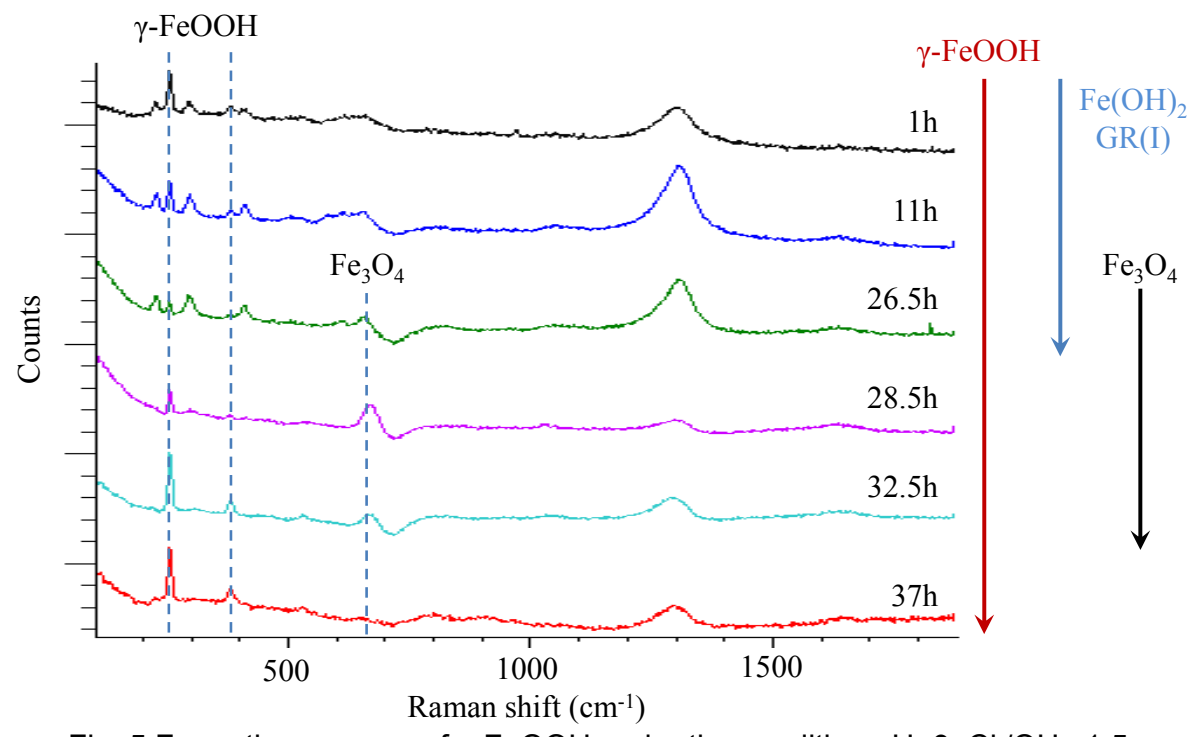

Fig. 5 Formation process of $\gamma$-FeOOH under the condition $\mathrm{pH}=9, \mathrm{Cl}^{-} / \mathrm{OH}^{-}=1.5$. 
concentration causing a lower corrosion rate, which made it difficult for the dissolved oxygen in the water film to be consumed. In addition, the fact that concentration of dissolved oxygen in water film became lower as $\mathrm{Cl}^{-}$concentration became higher (Ohkubo 2000) can be one of the reasons.

Previously, the authors have reported that formation amount of $\mathrm{Fe}_{3} \mathrm{O}_{4}$ increased when reinforcing steel in concrete is corroded by salt spray, whereas the formation amount of $\gamma$-FeOOH increased when steel-reinforced concrete specimens were exposed nearby fishing port for 26 years. In the report, it was considered that regularly sprayed salt water consequently kept the moisture level in concrete high (Nishizawa et al. 2013). The results obtained in this experiment seem to support those observations.

\section{Formation process of steel corrosion products in alkaline environment}

Summarizing the above results, the formation process of corrosion products in alkaline environment can be described as shown in Fig. 8. In the figure, intermediate products are colored light blue, and stable products are colored light brown.

In high alkaline environment, steel is protected from corrosion by formation of crystallized and stable $\mathrm{Fe}_{3} \mathrm{O}_{4}$. As $\mathrm{pH}$ decreases or chloride ion concentration increases, the formation amount of $\mathrm{Fe}_{3} \mathrm{O}_{4}$ becomes less due to reduction of its crystallinity and stability, and $\gamma-\mathrm{FeOOH}$ is formed easily instead. Formation of $\beta-\mathrm{FeOOH}$ was not observed in this study. However, considering the results of a previous study (Jambor et al. 1998), there is a possibility that $\beta-\mathrm{FeOOH}$ is formed under an environment where chloride ion exists and the $\mathrm{pH}$ has dropped to levels lower than 7 due to the propagation of corrosion.

Though $\alpha$-FeOOH was not observed in this study too, it has been reported that $\mathrm{Fe}^{3+}$ generated by the dissolution of $\mathrm{Fe}_{3} \mathrm{O}_{4}, \beta$ - $\mathrm{FeOOH}$ or $\gamma$ - $\mathrm{FeOOH}$ changes into thermodynamically stable $\alpha$-FeOOH with time (Misawa 2001), the process is called aging. Therefore, although there is a sufficient possibility that $\alpha-\mathrm{FeOOH}$ is formed in a condition of $\mathrm{Fe}_{3} \mathrm{O}_{4}$ or $\gamma$-FeOOH being easy to dissolve, it can be thought that there was not enough time for the formation of $\alpha-\mathrm{FeOOH}$ in this experiment. It should also be noted that $\mathrm{Fe}_{3} \mathrm{O}_{4}$ can be formed due to lack of dissolved oxygen although in conditions which $\gamma$-FeOOH is formed easily.

When $\mathrm{Fe}_{3} \mathrm{O}_{4}$ is stable, change into other compounds is difficult. Considering that, since reinforcing steel is generally used with mill scale, it can be said that in concrete, the steel is not protected by a passive film but by the mill scale. This is because $\mathrm{Fe}_{3} \mathrm{O}_{4}$, the main component of mill scale, is stable in alkaline environment, and does not change into a passive film.

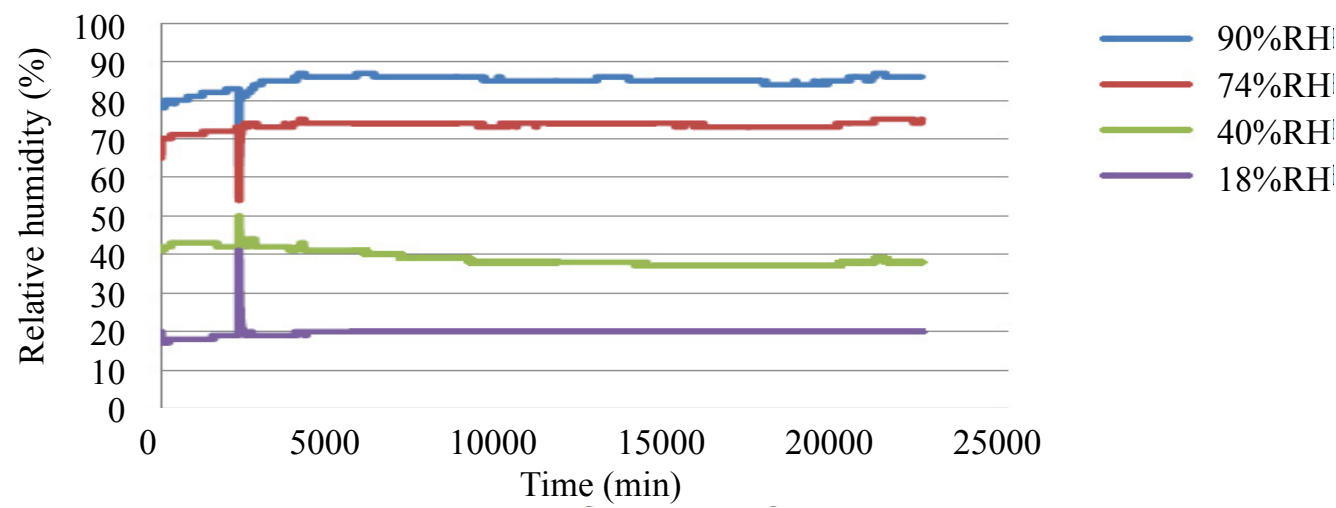

Fig. 6 Measured relative humidity.

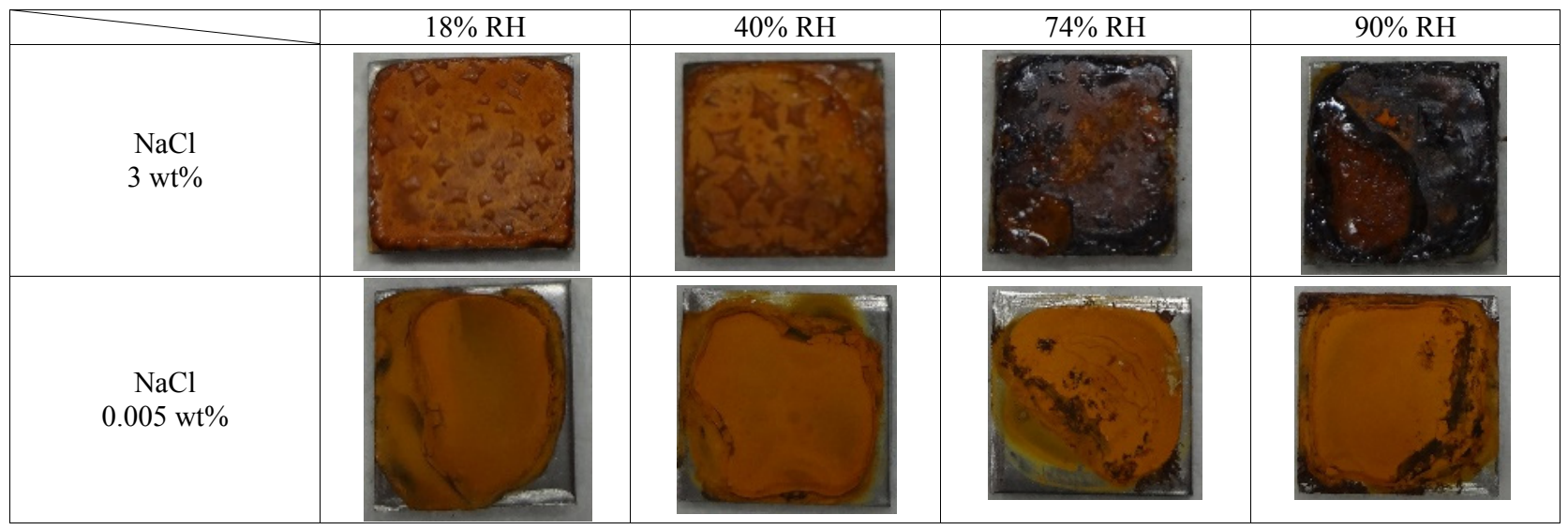

Fig. 7 Appearances of corrosion products formed. 
Table 3 Classification of corrosion environment.

\begin{tabular}{|c|c|c|c|c|}
\hline Classification & Environment & Corrosion products & Corrosion Rate & Volumetric expansion ratio \\
\hline $\mathrm{A} 1$ & Dry & $\gamma-\mathrm{FeOOH}$ & Low & about 3.1 \\
\hline $\mathrm{A} 2$ & $\begin{array}{c}\text { Wet } \\
\text { (rich oxygen) }\end{array}$ & $\begin{array}{l}\beta \text {-FeOOH } \\
\gamma \text {-FeOOH }\end{array}$ & Very high & Flow out \\
\hline B & $\begin{array}{c}\text { Wet } \\
\text { (poor oxygen) }\end{array}$ & $\begin{array}{c}\mathrm{Fe}_{3} \mathrm{O}_{4} \\
\alpha-\mathrm{FeOOH}\end{array}$ & Low & about 2.5 \\
\hline $\mathrm{C}$ & Wet and dry cycle & $\begin{array}{c}\gamma \text {-FeOOH (surface) } \\
\mathrm{Fe}_{3} \mathrm{O}_{4} \text { (layered) }\end{array}$ & High to Very high & about 2.1 \\
\hline
\end{tabular}

\section{Corrosion products formed in existing structures}

\subsection{Purpose}

This paper has described an experimental investigation of the effects of $\mathrm{pH}$ level, chloride ions, dissolved oxygen, and other factors on the formation of corrosion products. Recognizing that these factors are likely to interact in complex ways in the environment in which steel reinforced concrete is actually used, a survey of the corrosion products that form on reinforcing steel in actual concrete structures and classification of the corrosion environments was carried out.

In this study, 20 structures from the Tohoku region to the Kyushu region in Japan were surveyed, with focus on road and railway bridges.

\subsection{Corrosion environment of each structure}

As results of analysis of corrosion products obtained from actual concrete structures, it was made clear that the corrosion environment can be classified into the four types shown in Table 3. The corrosion products described in the table are based on the results of analysis of rust collected in the field so far, and the corrosion rate was estimated based on the formation mechanism of corrosion products in each environment. The volumetric expansion rate is the value estimated from the number, atomic weight, and density of each atom (Takaya et al. 2013).

The type of corrosion environment of each structure is arranged in Table 4. From the table, it is obvious that the environment of more than $70 \%$ of the structures was one of wet and dry cycles, and it can be said that main cause of corrosion propagation of reinforcement in Japan is this wet and dry cycle environment. Example photographs of reinforcement corroded under each environment are shown in Fig. 9.

\subsection{Propagation process of corrosion in each environment}

Considering the formation process of corrosion products obtained in this study, the process of propagation of corrosion in each environment can be explained as below.

\subsubsection{A1: Dry environment}

The oxidizing effects of air cause red-colored rust $(\gamma-\mathrm{FeOOH})$ to form on the surface of the reinforcing steel

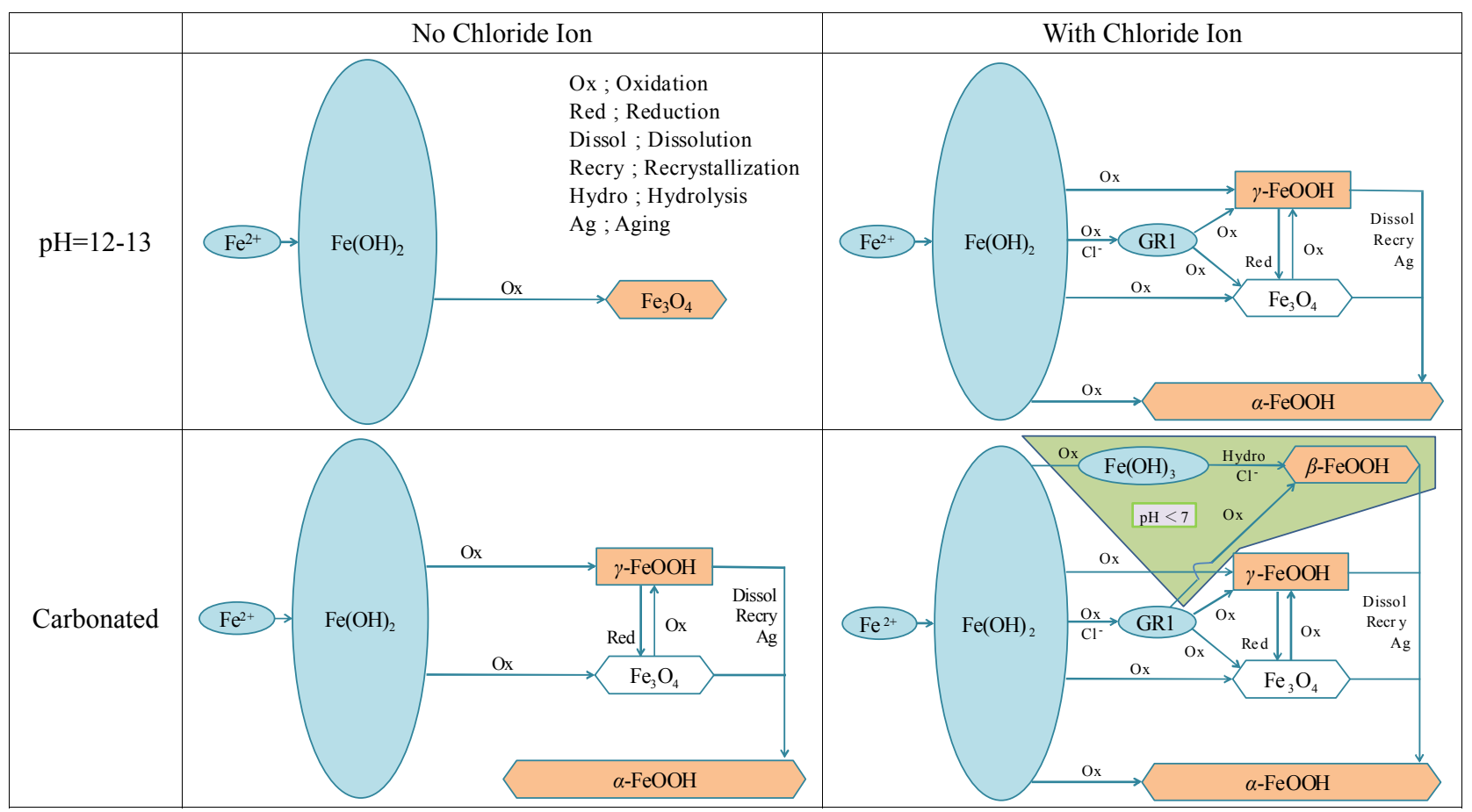

Fig. 8 Formation process of steel corrosion products in alkaline environment. 
Table 4 Classification of corrosion environment of existing structures.

\begin{tabular}{|c|c|c|c|c|}
\hline Structure & $\begin{array}{l}\text { Road bridge } \\
\text { slab }\end{array}$ & $\begin{array}{c}\text { Road bridge } \\
\text { slab }\end{array}$ & $\begin{array}{l}\text { Road bridge } \\
\text { girder }\end{array}$ & $\begin{array}{c}\text { Road bridge } \\
\text { pier }\end{array}$ \\
\hline Classification & $\mathrm{C}$ & $\mathrm{B}$ & $\mathrm{C}$ & A1 \\
\hline Structure & $\begin{array}{l}\text { Road bridge } \\
\text { girder }\end{array}$ & $\begin{array}{c}\text { Railway bridge } \\
\text { pier }\end{array}$ & $\begin{array}{c}\text { Railway bridge } \\
\text { pier }\end{array}$ & $\begin{array}{c}\text { Railway bridge } \\
\text { pier }\end{array}$ \\
\hline Classification & $\mathrm{B}$ & $\mathrm{C}$ & $\mathrm{C}$ & $\mathrm{C}$ \\
\hline Structure & $\begin{array}{c}\text { Railway bridge } \\
\text { girder }\end{array}$ & $\begin{array}{l}\text { Road bridge } \\
\text { slab }\end{array}$ & $\begin{array}{l}\text { Road bridge } \\
\text { girder }\end{array}$ & $\begin{array}{c}\text { Railway bridge } \\
\text { pier }\end{array}$ \\
\hline Classification & $\mathrm{C}$ & $\mathrm{C}$ & $\mathrm{A} 2$ & $\mathrm{C}$ \\
\hline Structure & $\begin{array}{c}\text { Railway bridge } \\
\text { girder }\end{array}$ & $\begin{array}{c}\text { Road bridge } \\
\text { abutment }\end{array}$ & $\begin{array}{c}\text { Road } \\
\text { box culvert }\end{array}$ & $\begin{array}{l}\text { Road bridge } \\
\text { abutment }\end{array}$ \\
\hline Classification & $\mathrm{C}$ & $\mathrm{C}$ & $\mathrm{C}$ & $\mathrm{C}$ \\
\hline Structure & $\begin{array}{l}\text { Road bridge } \\
\text { girder }\end{array}$ & $\begin{array}{l}\text { RC building } \\
\text { wall }\end{array}$ & $\begin{array}{l}\text { RC building } \\
\text { wall }\end{array}$ & $\begin{array}{l}\text { Road bridge } \\
\text { railing }\end{array}$ \\
\hline Classification & $\mathrm{C}$ & $\mathrm{C}$ & $\mathrm{B}$ & $\mathrm{C}$ \\
\hline
\end{tabular}

due to an environment that tends to dry readily. Under stable dry environment, it is difficult for the $\gamma$-FeOOH formed to change into other products because of the lack of water and because the rust layer functions to resist the diffusion of oxygen and iron ions. Consequently, corrosion rate is relatively low.

\subsubsection{A2: Wet environment (rich oxygen)}

In structures located in a wet environment that is greatly affected by water, when large voids due to segregation or bleeding exist between concrete and reinforcement surface, then water does not function as a water film but acts similar to bulk flowing water. Consequently, oxygen on the surface of the reinforcement is kept rich, resulting in the formation of $\gamma$-FeOOH. In case $\mathrm{Cl}^{-}$concentration is high, and the $\mathrm{pH}$ of the steel surface decreases due to corrosion propagation, $\beta$-FeOOH may form. Since the corrosion products formed are easily dissolved in water, and the rust layer does not function as a diffusion resistant layer on the surface of the steel, the corrosion rate is likely high and is sometimes accompanied by pitting as shown in Fig. 9.

\subsubsection{B: Wet environment (poor oxygen)}

In a wet environment, the moisture level around the surface of reinforcing steel is kept high, and because of the action of the water film, a thin layer of black rust $\left(\mathrm{Fe}_{3} \mathrm{O}_{4}\right)$ is formed on the surface of the reinforcement. Additionally, in the process of dissolution and recrystallization of $\mathrm{Fe}_{3} \mathrm{O}_{4}$, thermodynamically stable $\alpha$-FeOOH is formed on the surface of the steel. Because the rust layer works as a diffusion resistant one and oxygen necessary for corrosion is lacking, corrosion rate is kept relatively low.

\subsubsection{C: Wet and dry cycle environment}

Repeated wet and dry cycles result in the formation of thick black rust $\left(\mathrm{Fe}_{3} \mathrm{O}_{4}\right)$ layers as shown in Fig. 9. The formation mechanism of thick rust layer can be explained through Fig. 10.

$\mathrm{Fe}_{3} \mathrm{O}_{4}$ forms readily in wet environments, because water that has penetrated between concrete and reinforcing steel functions to resist the diffusion of oxygen. When conditions change to dry environment, the water is replaced by air, causing a part of rust layer on the surface to turn into $\gamma$-FeOOH due to the oxidizing effects of the air. When conditions become wet once again, the $\gamma$-FeOOH that had formed on the surface of rust layer dissolves and changes into $\mathrm{Fe}_{3} \mathrm{O}_{4}$. Since this process is a reducing reaction, an oxidation reaction is accompanied as the pair reaction. The surface of steel is therefore oxidized as the pair reaction of reduction of $\gamma-\mathrm{FeOOH}$

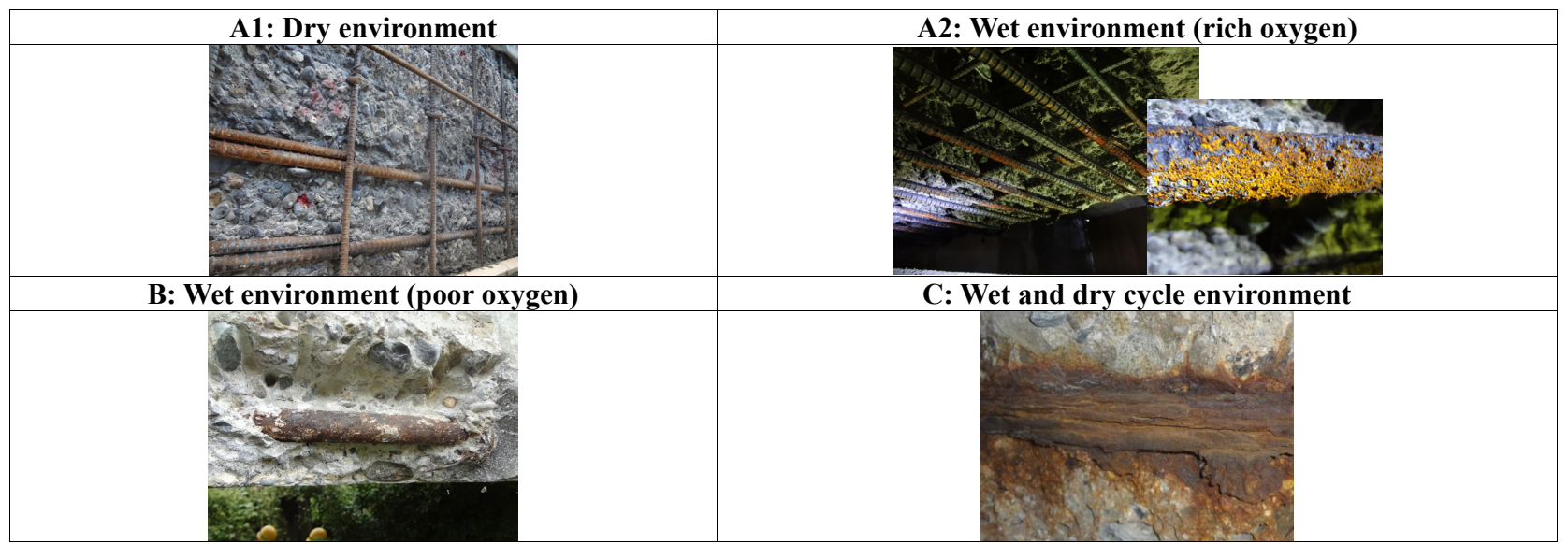

Fig. 9 Examples of reinforcement corroded in each environment. 
Table 5 Mix proportion of concrete.

\begin{tabular}{|c|c|c|c|c|c|}
\hline \multirow{2}{*}{$\mathrm{W} / \mathrm{C}$} & \multicolumn{5}{|c|}{ Unit amount $\left(\mathrm{kg} / \mathrm{m}^{3}\right)$} \\
\hline & W & C & $\mathrm{S}$ & G & $\mathrm{NaCl}$ \\
\hline \multirow{2}{*}{0.5} & \multirow{2}{*}{209} & \multirow{2}{*}{429} & \multirow{2}{*}{825} & \multirow{2}{*}{821} & 0 \\
\hline & & & & & 5 \\
\hline \multirow{2}{*}{0.6} & \multirow{2}{*}{212} & \multirow{2}{*}{354} & \multirow{2}{*}{883} & \multirow{2}{*}{810} & 0 \\
\hline & & & & & 5 \\
\hline
\end{tabular}

(Misawa 2001), causing the formation of a new $\mathrm{Fe}_{3} \mathrm{O}_{4}$ layer under the bottom rust layer closest to the surface of steel. Repetition of this process final results in the formation of a thick rust layer of $\mathrm{Fe}_{3} \mathrm{O}_{4}$.

In summary, although existence of $\mathrm{Cl}^{-}$and drop of $\mathrm{pH}$ due to carbonation can be trigger of reinforcement corrosion, after that stage the influences of water and oxygen on corrosion propagation are much larger than that of $\mathrm{Cl}^{-}$concentration or $\mathrm{pH}$. Therefore, the corrosion rate itself depends on the environment.

\section{Influence of W/C and $\mathrm{Cl}^{-}$on behavior of moisture in concrete}

\subsection{Purpose}

The discussions above make it clear that the behavior of moisture in concrete has large influence on reinforcement corrosion. However, the behavior of moisture in concrete as a factor of corrosion is still unclear. Therefore, in order to obtain basic information on the behavior of moisture in concrete, the change of humidity inside concrete against the change of ambient humidity was investigated.

\subsection{Experimental details}

Concrete specimens with a diameter of $150 \mathrm{~mm}$ and height $150 \mathrm{~mm}$ were used in the experiment, and the bottom surfaces when casting the specimens were used as the cover surfaces. In order to investigate humidity inside of concrete, waterproof type humidity sensors were embedded inside the concrete during setting, so that cover thickness became $30 \mathrm{~mm}$. Corrosion sensors were also embedded in order to investigate wetness (solution resistance) inside of concrete. The experimental factors were $\mathrm{W} / \mathrm{C}(0.5$ and 0.6$)$ and $\mathrm{Cl}^{-}$content $\left(0 \mathrm{~kg} / \mathrm{m}^{3}\right.$ and 3.03 $\left.\mathrm{kg} / \mathrm{m}^{3}\right)$. Three specimens were prepared for each combination of $\mathrm{W} / \mathrm{C}$ and $\mathrm{Cl}^{-}$content. The mix proportion of the concrete is shown in Table 5. Ordinary Portland cement was used, and the maximum diameter of coarse aggregate was $15 \mathrm{~mm}$. Air content was designed to be $5.0 \%$, and the targeted slump was $8.0 \pm 2.0 \mathrm{~cm}$.

After 7 days underwater curing, pre-drying was carried out for 32 days in the laboratory, where the average temperature was $17^{\circ} \mathrm{C}$. After pre-curing, specimens were dried in three desiccators containing silica gel for 120 days (including the pre-drying period). The temperature in the desiccators was kept $20^{\circ} \mathrm{C}$. In each desiccator, four types of specimens were put in one by one. Silica gel was exchanged regularly so that water vapor evaporated from specimens could be removed.

\subsection{Results and discussion}

Figure 11 shows the average mass reduction rate of each type of specimen during drying. From the figure, it is obvious that the mass reduction rate tends to be higher in the case of large $\mathrm{W} / \mathrm{C}$. In the case of $\mathrm{W} / \mathrm{C}=0.6$, the mass reduction rate was large, particularly in the early stage of drying. It can be thought that this is because the ratio of water in specimen volume becomes larger as $\mathrm{W} / \mathrm{C}$ becomes large. Comparing specimens of the same $\mathrm{W} / \mathrm{C}$, the

Wet Environment

\begin{tabular}{c|l}
\multicolumn{1}{c|}{$\mathrm{Fe}_{3} \mathrm{O}_{4}$} & $\begin{array}{l}\mathrm{Fe}_{3} \mathrm{O}_{4} \text { is formed because water } \\
\text { Reinforcement }\end{array}$ \\
$\begin{array}{l}\text { layer work as diffusion } \\
\text { resistance of oxygen }\end{array}$
\end{tabular}

Dry Environment \begin{tabular}{|c|l|}
\hline (2) $\gamma-\mathrm{FeOOH}$ & $\begin{array}{l}\text { Surface of rust layer turn into } \\
\text { (1) } \mathrm{Fe}_{3} \mathrm{O}_{4}\end{array}$ \\
$\begin{array}{c}\gamma \text {-FeOOH because of air } \\
\text { oxydation }\end{array}$ &
\end{tabular}

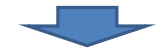

Wet Environment

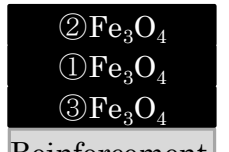

Reinforcement

$\gamma$-FeOOH dissolve and reduced

into $\mathrm{Fe}_{3} \mathrm{O}_{4}$

Then reinforcing steel is oxidized and new $\mathrm{Fe}_{3} \mathrm{O}_{4}$ layer is formed

$$
\begin{aligned}
& \mathrm{Fe} \rightarrow \mathrm{Fe}^{2+}+2 \mathrm{e}^{-} \\
& \mathrm{Fe}^{2+}+8 \gamma-\mathrm{FeOOH}+2 \mathrm{e}^{-} \rightarrow 3 \mathrm{Fe}_{3} \mathrm{O}_{4}+4 \mathrm{H}_{2} \mathrm{O}
\end{aligned}
$$

Fig. 10 Formation mechanism of black rust layer in wet and dry cycle environment. 
mass reduction rate tends to be lower in the case of specimens containing $\mathrm{Cl}^{-}$.

As an example, the change of humidity change of each specimen in one desiccator is shown in Fig. 12. In the case of the specimens containing $\mathrm{Cl}^{-}$, humidity obviously tends to decrease rapidly in the early stage of drying when compared to those without $\mathrm{Cl}^{-}$. This characteristic behavior under the existence of $\mathrm{Cl}^{-}$was observed in specimens of another desiccator.

The reason why humidity started to decrease at an early stage in the case of the specimens containing $\mathrm{Cl}^{-}$ can be explained as follows: When the moisture on the surface area is easily dried and dispersed, a concentration gradient of $\mathrm{Cl}^{-}$occurs between the surface and interior of the concrete, and in order to ease the concentration gradient, moisture is transferred from inner to surface by osmotic pressure. Therefore, it can be considered that the moisture transfer rate become high in concrete containing $\mathrm{Cl}^{-}$. Furthermore, considering the result of mass reduction rate, it can also be said that although $\mathrm{NaCl}$ tends to adsorb moisture because of its deliquescence, the adsorbed moisture does not contribute to humidity because it works as combined one.

In order to investigate the influence of deliquescence of $\mathrm{NaCl}$, outdoor (rainy environment) exposure was carried out after drying in a desiccator, and the wetness of the specimens was evaluated by solution resistance measured using AC impedance. Figure 13 shows the change of solution resistance of each specimen. The figure makes it clear that the solution resistance of the $\mathrm{Cl}^{-}$ containing specimens is constantly lower than that of the specimens without $\mathrm{Cl}^{-}$. This result shows that the wetness inside concrete becomes higher when $\mathrm{Cl}^{-}$is contained in concrete.

However, the solution resistance of concrete without $\mathrm{Cl}^{-}$was not so high (about $10000 \mathrm{ohms}$ ) though it should be noted that solution resistance would be influenced by temperature. Solution humidity tends to become higher as temperature goes down. Therefore, one of the causes was that outdoor temperature was lower than temperature in the desiccator $\left(20^{\circ} \mathrm{C}\right)$. When considering that humidity in the dry environment is lower than $74 \% \mathrm{RH}$, which is the humidity level where $\mathrm{NaCl}$ shows deliquescence (Oshikawa et al. 2003), it can be inferred from Fig. 12 that it takes longer than 50 days for drying the interior of concrete even in an environment where atmospheric humidity is sufficiently low. Therefore, it can be thought that the interior of concrete is constantly wet under rainy

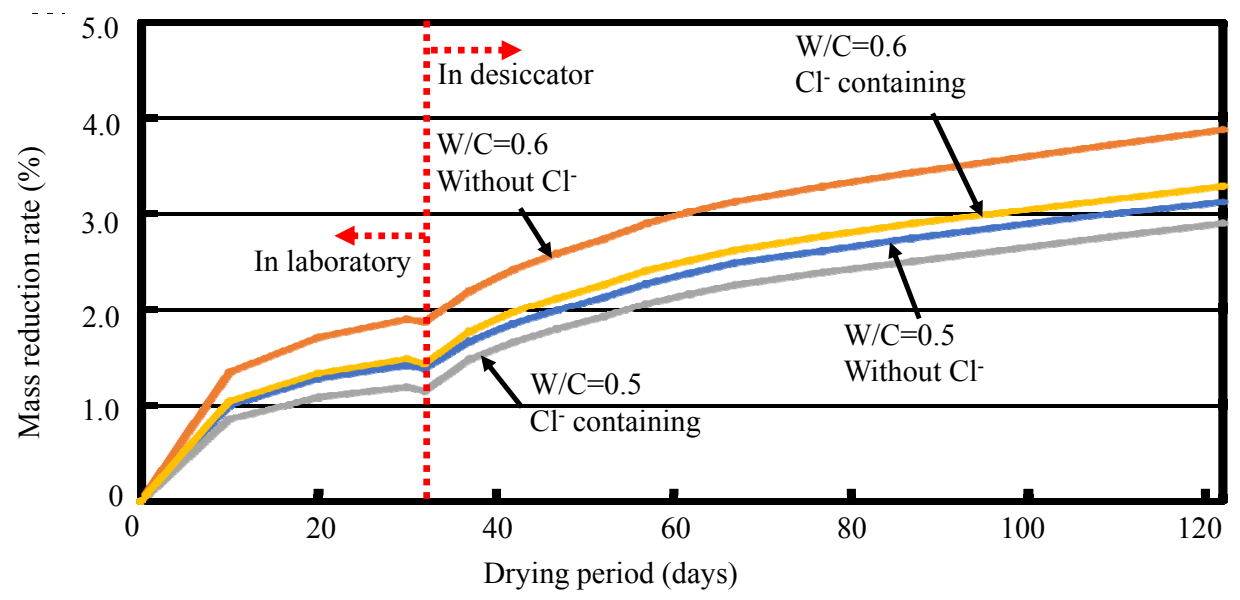

Fig. 11 Mass reduction rate of each specimen.

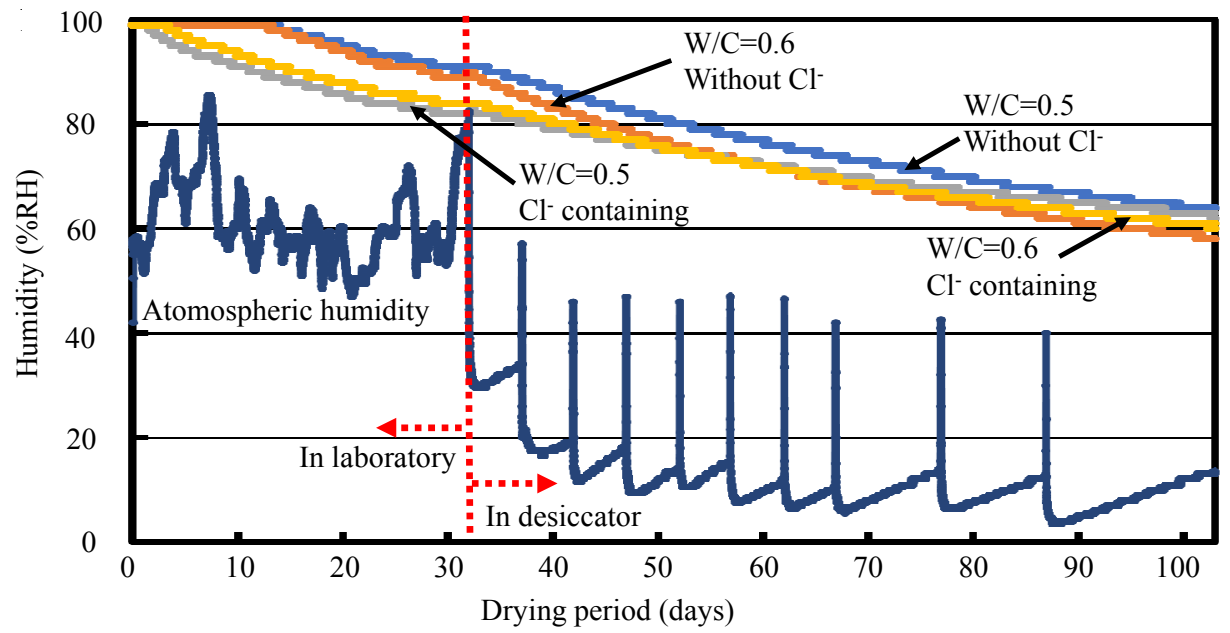

Fig. 12 Humidity change in each specimen. 
environment regardless of $\mathrm{Cl}^{-}$content.

\section{Influence of cracks on behavior of moisture in concrete}

\subsection{Purpose}

From the above discussions, it was indicated that inside of concrete is constantly wet under rainy environment even when $\mathrm{Cl}^{-}$is not contained. This indicates a possibility that the reason for wet and dry cycles being the main cause of corrosion propagation in existing structures is the existence of cracks. Therefore, the influence of cracks on humidity change inside concrete was investigated using mortar specimens. Mortar specimens were used because control of crack width in case of concrete is difficult as it is influenced largely by coarse aggregate.

\subsection{Experimental details}

Mortar specimens of size $100 \times 200 \times 200 \mathrm{~mm}$ prepared using ordinary Portland cement were used in the experiment to investigate the effect of crack width, with the bottom surfaces during casting being used as the cover surfaces. Waterproof type humidity sensors were embedded so that cover thickness became $20 \mathrm{~mm}$. The sand cement ratio was 3.0 , and $\mathrm{W} / \mathrm{C}$ was 0.5 . Three specimens were prepared for $\mathrm{W} / \mathrm{C}=0.5$ with crack and $\mathrm{W} / \mathrm{C}=0.5$ without crack. In order to investigate difference with concrete specimens, three $\mathrm{W} / \mathrm{C}=0.6$ mortar specimens without crack were also prepared.

After 7 days of underwater curing, drying was carried out for 120 days in a desiccator where humidity was controlled to be $60 \%$. Cracks were induced to mortar specimens by 3 point bending at 28 days after the start of drying. Before 3 point bending, a slit with both depth and width of $1 \mathrm{~mm}$ was induced on specimen's surface just above humidity sensor for guidance of crack-induced position. The crack widths measured on surface of the 3 specimens were $0.04 \mathrm{~mm}, 0.08 \mathrm{~mm}$ and $0.1 \mathrm{~mm}$ (see Table 6). The numbers in brackets indicate the number of specimens for each condition.

\subsection{Results and discussion}

Figure 14 shows the average humidity change of the three uncracked specimens. It is seen from Fig. 12 that although the average atmospheric humidity during

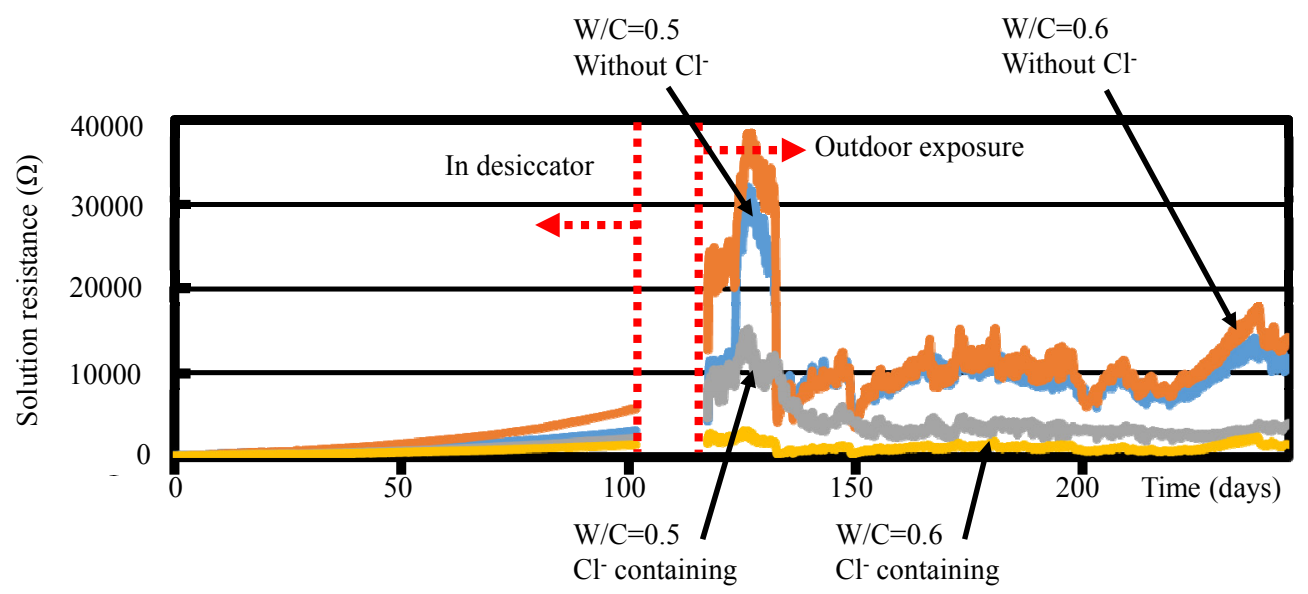

Fig. 13 Solution resistance change of each specimen.

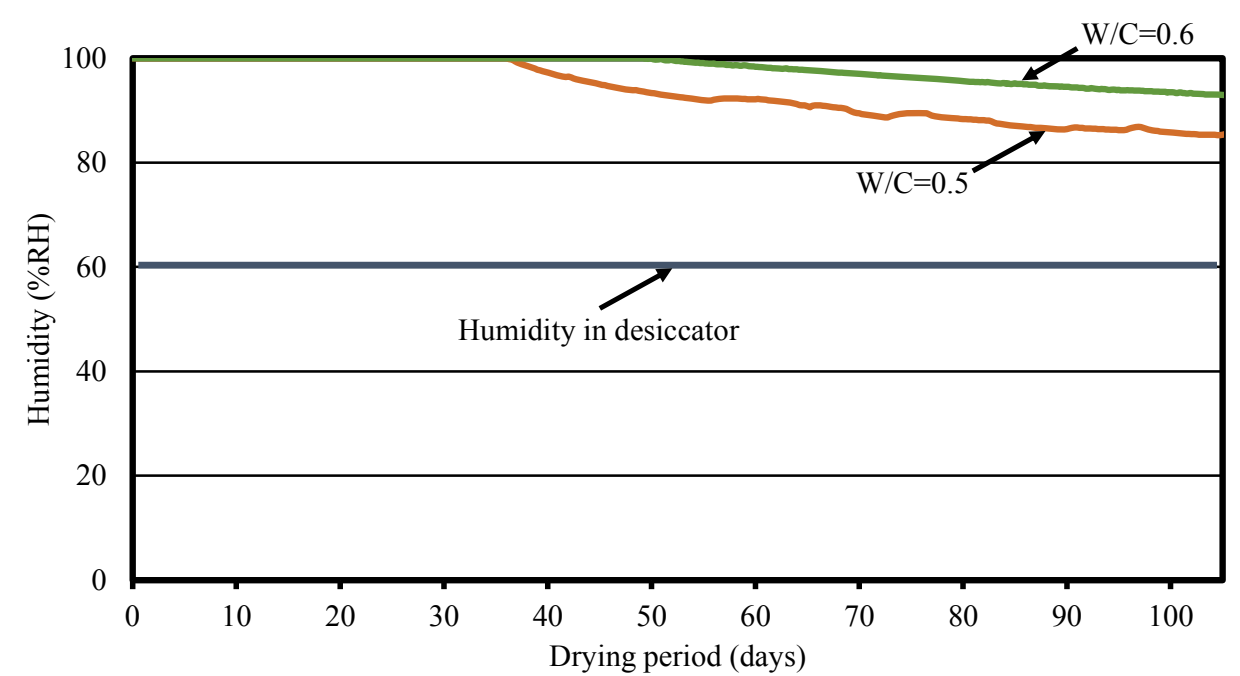

Fig. 14 Humidity change of mortar specimens without crack. 
Table 6 Mortar specimens used to investigate the influence of cracks on humidity.

\begin{tabular}{|c|c|c|c|c|}
\hline W/C & \multicolumn{4}{|c|}{ Crack width $(\mathrm{mm})$} \\
\hline 0.5 & $0\left(3^{*}\right)$ & $0.04\left(1^{*}\right)$ & $0.08\left(1^{*}\right)$ & $0.1\left(1^{*}\right)$ \\
\hline 0.6 & $0\left(3^{*}\right)$ & - & - & - \\
\hline
\end{tabular}

${ }^{*}$ The figures within brackets indicate the number of specimens.

pre-curing was about 60 to $70 \% \mathrm{RH}$, the humidity inside the concrete falls to about $90 \% \mathrm{RH}$ within 30 days even in the cases without $\mathrm{Cl}^{-}$. It can be seen from Fig. 14 that in the case of mortar, however, the humidity did not change within 30 days after the start of drying under $60 \%$ RH. This would be because the unit water volume of mortar was larger than that of concrete. Furthermore, in the case of $\mathrm{W} / \mathrm{C}=0.6$, the time for change of humidity was longer than $\mathrm{W} / \mathrm{C}=0.5$ and the final humidity change was smaller.

Figure 15 shows the mass reduction rate of mortar specimens without cracks. From the figure, it is obvious that the mass reduction rate of the $\mathrm{W} / \mathrm{C}=0.6$ specimen is larger than that of $\mathrm{W} / \mathrm{C}=0.5$. It implies that the total moisture dispersion would be high in the case of $\mathrm{W} / \mathrm{C}=0.6$, although it is difficult for the humidity in the interior to drop. The reason for this can be thought to be as follows: $\mathrm{The} \mathrm{W} / \mathrm{C}=0.6$ specimen originally contains a larger amount of excess moisture than $\mathrm{W} / \mathrm{C}=0.5$ specimen. When moisture dispersed from the surface area, moisture would be provided from inner side by diffusion, resulting in longer time necessary for drying of humidity sensor depth.

Figure 16 shows the humidity change of $\mathrm{W} / \mathrm{C}=0.5$ mortar specimens with cracks. For comparison, the data of specimen without crack is also shown. It is clear from the figure that the $0.04 \mathrm{~mm}$ width crack did not have any influence on humidity change. However, in the case of cracks of $0.08 \mathrm{~mm}$ and $0.1 \mathrm{~mm}$ width, there was obvious change in the humidity, the change being observed just after inducing the cracks. Since it was confirmed that humidity changes inside of concrete was much larger

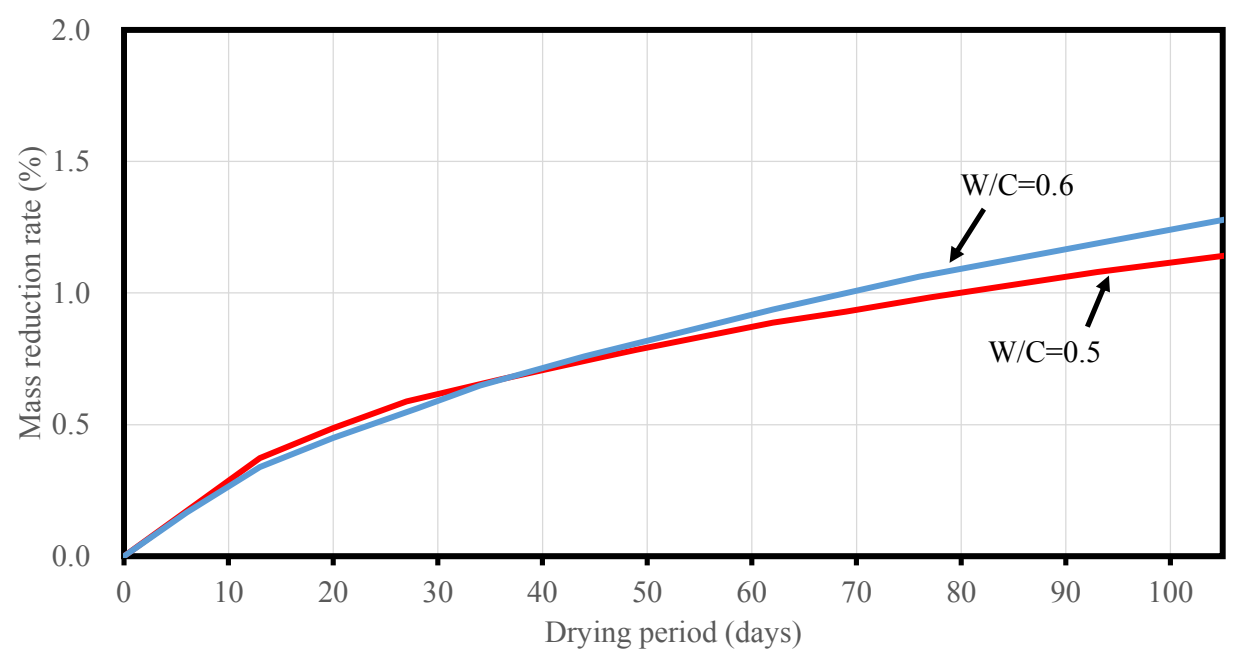

Fig. 15 Mass reduction rate of mortar specimens without crack.

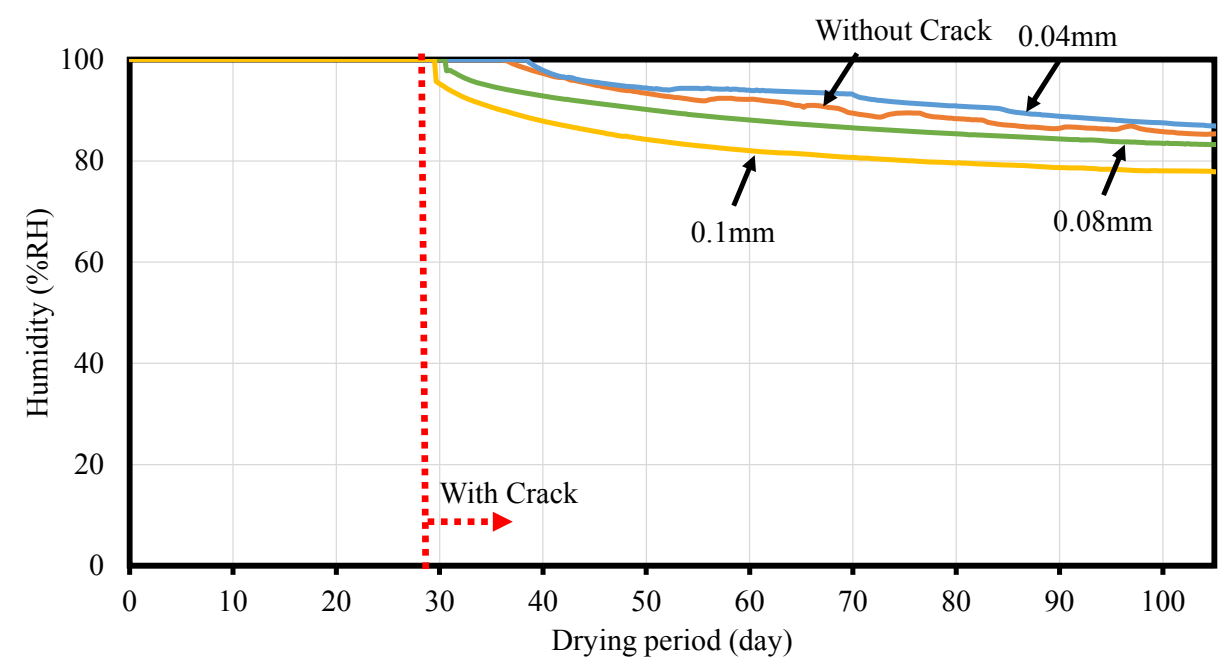

Fig. 16 Influence of crack on humidity change inside of mortar. 
Table 7 Amounts of corrosion amount corresponding to $10 \%$ of each diameter of reinforcement.

\begin{tabular}{|c|c|c|c|c|c|c|c|}
\hline & D13 & D16 & D19 & D22 & D25 & D29 & D32 \\
\hline $\begin{array}{c}\text { Amount of corrosion } \\
\left(\mathrm{mg} / \mathrm{cm}^{2}\right)\end{array}$ & 255 & 314 & 373 & 432 & 491 & 569 & 628 \\
\hline
\end{tabular}

than that of mortar, in case of concrete there is a possibility that the influence of cracks become larger. However, from this result, at least it can be said that cracks of $0.08 \mathrm{~mm}$ or more in width have influence on wet and dry cycle to some extent.

\section{Proposal of a maintenance scenario for concrete structures damaged by reinforcement corrosion}

\subsection{Purpose}

As a result of this study, it was made clear that corrosion environment of steel in concrete can be classified into four types and that corrosion propagates especially under wet and dry cycle environments. On the other hand, it was confirmed that it would be difficult to disperse moisture in concrete without cracks, and that continuous drying of more than 50 days would be necessary even in a sufficiently dry environment. Therefore, in the case of concrete without cracks, it can be thought that the interior would be in constantly wet environment except under dry environment. In addition, it was also confirmed that cracks of at least $0.08 \mathrm{~mm}$ or more have an influence on drying of inside of concrete.

Based on the above results from this study, the authors propose a maintenance method based on the mechanism of corrosion of steel and the behavior of moisture in concrete. Since corrosion cracks expand with the corrosion propagation, crack width can be an index for knowing the degree of corrosion.

The maintenance method proposed here takes the width of crack induced by corrosion as an index of the degree of corrosion. According to past studies, the structural load-carrying capacity is reduced largely because of fracture of the reinforcing steel or cross-section losses exceeded 10\% due to local corrosion (Yamamoto et al. 2018). Therefore, in this study, the limiting crack width was set to be the crack width when the cross-section loss is $10 \%$. The amount of corrosion corresponding to $10 \%$ cross-section loss of each diameter of reinforcement is as shown in Table 7.

Based on the above, it is suggested that concrete structures damaged by reinforcement corrosion should be maintained so that crack widths do not exceed the limit crack width.

\subsection{Calculation method of limit crack width}

It is known that the cover thickness, strength of concrete (Yamamoto et al. 2018; Qi et al. 2001; Andrade et al. 1993) and corrosion products (Nishizawa et al. 2013) influence the relationship between corrosion amount and crack width. Figure 17 shows the result of re-organizing the data in case of $20 \mathrm{~mm}$ cover thickness and $19 \mathrm{~mm}$ rebar diameter reported in a previous paper (Nishizawa $e t$ al. 2013). In previous studies, it was often considered that corrosion amount increases linearly with crack width $w$ (Yamamoto et al. 2018). In the figure, however, corrosion amount is approximated linearly with $\sqrt{w}$. It can be thought that this is because the slope of line changed after crack penetration into cover concrete.

In this paper, it was assumed that the amount of corrosion increases linearly with cover thickness, and Eq. (1) was used for calculation. In this equation, $W_{c}$ is the corrosion amount $\left(\mathrm{mg} / \mathrm{cm}^{2}\right), C$ is the cover thickness (mm), $\gamma$ is the volumetric expansion ratio, and $w$ is the

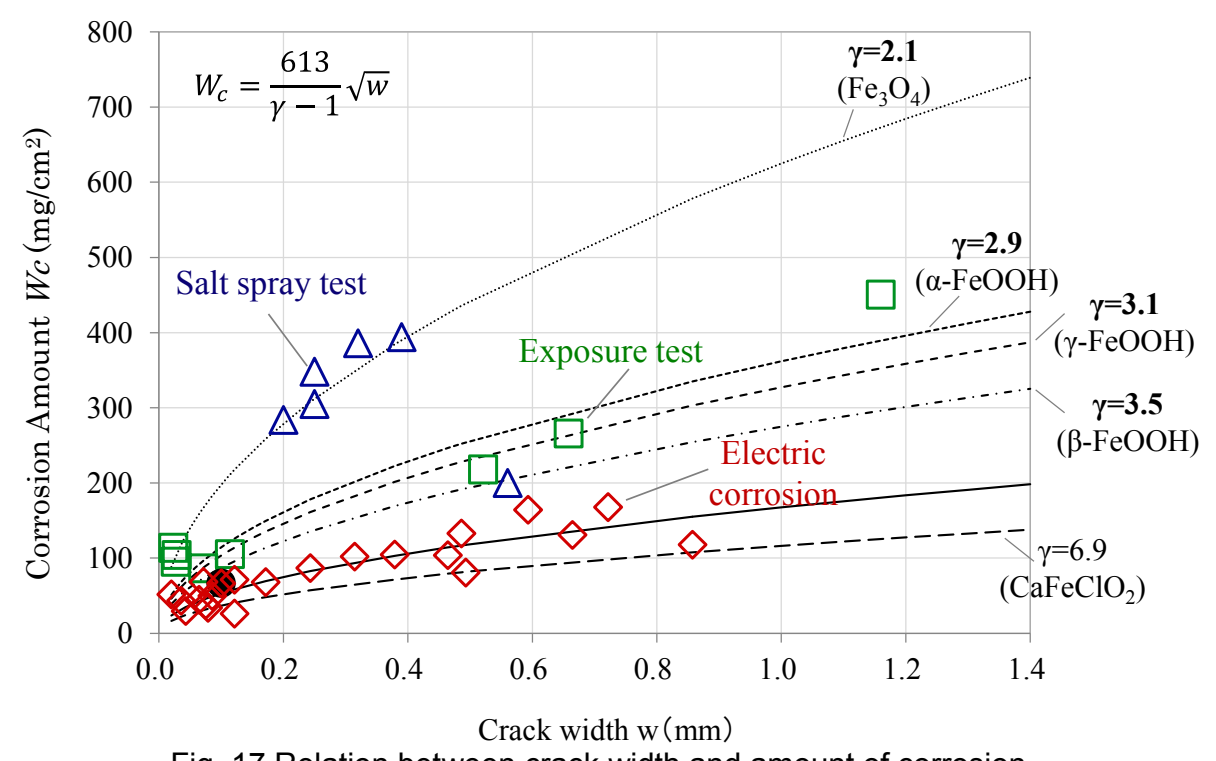

Fig. 17 Relation between crack width and amount of corrosion. 
Table 8 Limiting crack width under dry environment.

\begin{tabular}{|c|c|c|c|c|c|c|c|c|}
\hline & & D13 & D16 & D19 & D22 & D25 & D29 & D32 \\
\hline \multirow{5}{*}{ 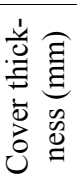 } & 20 & 0.7 & 1.3 & 1.6 & 2.1 & 2.8 & 3.7 & 4.6 \\
\hline & 30 & 0.3 & 0.5 & 0.7 & 0.9 & 1.2 & 1.6 & 2.0 \\
\hline & 40 & 0.1 & 0.2 & 0.4 & 0.5 & 0.7 & 0.9 & 1.1 \\
\hline & 50 & 0.1 & 0.1 & 0.2 & 0.3 & 0.4 & 0.5 & 0.7 \\
\hline & 60 & 0.05 & 0.1 & 0.1 & 0.2 & 0.3 & 0.4 & 0.5 \\
\hline
\end{tabular}

Table 9 Limiting crack width under wet environment (poor oxygen).

\begin{tabular}{|c|c|c|c|c|c|c|c|c|}
\hline & & D13 & D16 & D19 & D22 & D25 & D29 & D32 \\
\hline \multirow{5}{*}{ 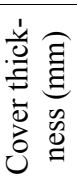 } & 20 & 0.3 & 0.5 & 0.8 & 1.0 & 1.5 & 2.0 & 2.3 \\
\hline & 30 & 0.2 & 0.2 & 0.3 & 0.4 & 0.6 & 0.8 & 1.0 \\
\hline & 40 & 0.05 & 0.1 & 0.2 & 0.2 & 0.3 & 0.4 & 0.5 \\
\hline & 50 & 0.05 & 0.05 & 0.1 & 0.1 & 0.2 & 0.3 & 0.3 \\
\hline & 60 & 0.05 & 0.05 & 0.05 & 0.1 & 0.1 & 0.2 & 0.2 \\
\hline
\end{tabular}

Table 10 Limiting crack width under wet and dry cycle environment.

\begin{tabular}{|c|c|c|c|c|c|c|c|c|}
\hline 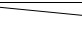 & & D13 & D16 & D19 & D22 & D25 & D29 & D32 \\
\hline \multirow{5}{*}{ 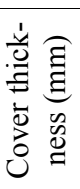 } & 20 & 0.2 & 0.3 & 0.4 & 0.5 & 0.7 & 1.0 & 1.3 \\
\hline & 30 & 0.1 & 0.1 & 0.1 & 0.2 & 0.3 & 0.4 & 0.5 \\
\hline & 40 & 0.05 & 0.05 & 0.1 & 0.1 & 0.1 & 0.2 & 0.3 \\
\hline & 50 & 0.05 & 0.05 & 0.05 & 0.05 & 0.1 & 0.1 & 0.2 \\
\hline & 60 & 0.05 & 0.05 & 0.05 & 0.05 & 0.05 & 0.1 & 0.1 \\
\hline
\end{tabular}

crack width (mm). The limit crack width was decided as the value for which calculated corrosion amount did not exceed the value shown in Table 7.

$$
W_{c}=\frac{613 C}{20(\gamma-1)} \sqrt{w}
$$

The reason why concrete strength was not considered in the equation is that the influence of concrete strength is thought to be less after cover cracking. Since the influence of bar diameter on the relationship between corrosion amount and crack width has not been clearly identified, bar diameter was excluded from this equation.

\subsection{Limit crack width in each corrosion envi- ronment}

Considering characteristics of corrosion products formed in each environment, it can be thought that the limiting crack width would be as below. Each limiting crack width shown in Tables $\mathbf{8}$ to $\mathbf{1 0}$ was calculated with the limiting corrosion amount shown in Table 7 and the equation above.

\subsubsection{Dry environment}

Steel in concrete can be in this corrosion environment when the supply of moisture is low and the structures are easily dried by sunlight or wind. In this case, it can be thought that the main corrosion product would be $\gamma$-FeOOH with volumetric expansion ratio of 3.1 , and the limiting crack width would be as shown in Table 8 . Although the crack growth rate is high, corrosion rate itself seems to be low if dry environment is kept.

\subsubsection{Wet environment (rich oxygen)}

Steel in concrete can be in this corrosion environment when outstanding honeycombs or material separation exist. In this case, it can be thought that the corrosion rate is very high and that enlargement of the cracks would be difficult because corrosion products flow out through cracks. Therefore, concrete structures under this environment are excluded from the maintenance method with limit crack width. If a large amount of rust fluid is observed through cracks in concrete structures with prominent defects such as honeycomb or material separation, it is desirable to take countermeasures as soon as possible.

\subsubsection{Wet environment (poor oxygen)}

Steel in concrete can be in this corrosion environment when moisture is provided to structures constantly. In addition, it is necessary that structures are under environment where drying by factors such as sunlight or wind is difficult. In this case, it can be thought that corrosion rate is low and that the main corrosion products would be $\mathrm{Fe}_{3} \mathrm{O}_{4}$ with volumetric expansion ratio of 2.1 and $\alpha-\mathrm{FeOOH}$ with volumetric expansion ratio of 2.9 . $\alpha-\mathrm{FeOOH}$ can be formed by aging under only wet environment. Consequently, volumetric expansion ratio of combined products seems to be about 2.5 . Consequently the limiting crack width would be as shown in Table 9.

Though corrosion rate itself is low if wet environment is kept, it should be also noted that there is a possibility that the environment changing to a wet and dry cycle environment due to growth of cracks.

\subsubsection{Wet and dry cycle environment}

Before occurrence of cracks, it can be thought that the environment of the concrete interior is wet. Steel in concrete, however, can be in this corrosion environment 
when interior of concrete is sometimes dried by sunlight or wind after corrosion cracks appear. In this environment, it can be thought that main corrosion product is $\mathrm{Fe}_{3} \mathrm{O}_{4}$ with volumetric expansion ratio of 2.1 , and the limiting crack width would be as shown in Table $\mathbf{1 0}$. Because volumetric expansion ratio of the corrosion product is relatively small and crack growth rate is low, limiting crack width is smaller than other environments. In this case, it can be thought that corrosion rate is high, although it depends on frequency of wet and dry cycle.

From the result of field survey carried out so far, the cover thickness of almost all structures damaged by reinforcement corrosion was less than $50 \mathrm{~mm}$. Though the cover thickness in one structure was $90 \mathrm{~mm}$, cracks induced by ASR were observed in it, and it can be thought that corrosion started after ASR cracking. That is to say, it can be thought that corrosion risk of structures with sufficiently large cover thickness would be originally low. Therefore, cover thicknesses larger than 60 $\mathrm{mm}$ was excluded from the tables. However, there is a possibility such structures would be damaged by corrosion because of cracks induced not by corrosion but by other causes such as ASR or drying shrinkage, etc. The limit crack width in the case of large cover thickness is small as shown in the tables. In the case of such structures, it is desirable to be take suitable countermeasures when cracks are observed.

Of course, there is a possibility that existing cracks cause corrosion in case of structures with small cover thickness. In these cases, it can be thought that leaving it until crack width reach to the limit crack width is one of the options. For example, when $0.1 \mathrm{~mm}$ cracks due to shrinkage are observed in structure cover thickness of 20 $\mathrm{mm}$ and bar diameter of $19 \mathrm{~mm}$, then it is one of option to leave it until crack width reach to $0.4 \mathrm{~mm}$, because propagation of crack after that seems to be only by corrosion. However, progressive cracks induced by such as ASR are excluded from this maintenance method.

\section{Conclusions}

In this study, the influence of $\mathrm{OH}^{-}, \mathrm{Cl}^{-}$and dissolved oxygen on corrosion products was investigated first in order to make clear the corrosion process in alkaline environment. In addition, the corrosion mechanism of steel in concrete was investigated based on field study, and the influence of $\mathrm{W} / \mathrm{C}, \mathrm{Cl}^{-}$and crack on the behavior of moisture in concrete was investigated. Finally, based on the results obtained, the authors propose a maintenance scenario of concrete structures damaged by reinforcement corrosion. The main conclusions obtained through this study are summarized below.

1) It can be thought that the component of passive films formed in acid environment is $\gamma-\mathrm{Fe}_{2} \mathrm{O}_{3}$ and those formed in alkaline environment is $\mathrm{Fe}_{3} \mathrm{O}_{4}$. However, in the general case of reinforcing steel with mill scale, it can be thought that reinforcing steel in concrete is protected not by the passive film but by the mill scale.
This is because $\mathrm{Fe}_{3} \mathrm{O}_{4}$, the main component of mill scale, is stable in alkaline environment.

2) Under high alkaline environment, steel is protected from corrosion by formation of crystallized and stable $\mathrm{Fe}_{3} \mathrm{O}_{4}$. As $\mathrm{pH}$ decreases or chloride ion concentration increases, formation amount of $\mathrm{Fe}_{3} \mathrm{O}_{4}$ become less due to reduction of its crystallinity and stability and $\gamma$-FeOOH is formed easily instead.

3) The influence of dissolved oxygen is large, and $\mathrm{Fe}_{3} \mathrm{O}_{4}$ can be formed due to lack of dissolved oxygen even under conditions where $\gamma$-FeOOH is formed easily. However, the crystallinity of $\mathrm{Fe}_{3} \mathrm{O}_{4}$ formed in unstable condition is poor and changes into $\gamma$-FeOOH easily when oxygen is supplied.

4) As results of survey of corrosion products formed in actual concrete structures, it was confirmed that corrosion environment can be classified into four types based on the difference how water and oxygen work. Especially in Japan, it can be thought that the wet and dry cycle is the main cause of corrosion propagation. It was also made clear that propagation rate itself would be dependent on the action of water and oxygen, although existence of chloride ions and drop of $\mathrm{pH}$ due to carbonation can be triggers of reinforcement corrosion.

5) It was confirmed that it is difficult to disperse the moisture in concrete without cracks, and that continuous drying of more than 50 days would be necessary even in a sufficiently dry environment. Therefore, in the case without cracks, it can be thought that the interior of concrete would be in a constantly wet environment except under dry environment. In addition, it was also confirmed that cracks of at least $0.08 \mathrm{~mm}$ or more have influence on drying of the interior of concrete.

6) Finally, a maintenance scenario for concrete structures with limiting crack width was suggested. The limiting crack width was set as the crack width when the amount of corrosion is $10 \%$ loss of cross section of the reinforcement. The limiting crack width in each corrosion environment was calculated based on re-organized data reported in the previous study.

\section{Acknowledgement}

A part of this study was supported by Cross-ministerial Strategic Innovation Promotion Program (SIP), "Infrastructure Maintenance, Renovation and Management", [Funding agency: Japan Science and Technoloy Agency (JST)].

\section{References}

Andrade, C., Alonso, C. and Molina, F. J., (1993). "Cover cracking as a function of rebar corrosion, Part-2: Numerical method." Materials and Structures, 26, 532-548.

Jambor, J. L. and Dutrizac, J. E., (1998). "Occurrence and constitution of natural and synthetic ferrihydrite, a widespread iron oxyhydroxide." Chemical Reviews, 
98, 2549-2585.

Misawa, T., Hashimoto, K. and Shimodaira, S. (1974). "On the mechanism of atmospheric rusting of iron and protective rust layer on low alloy steel." Boshoku-Gijutsu, 33, 17-27. (in Japanese)

Nieuwoudt, M. K., Comins, J. D. and Cukrowski, I., (2012). "Analysis on the composition of the passive film on iron under pitting conditions in $0.05 \mathrm{M}$ $\mathrm{NaOH} / \mathrm{NaCl}$ using Raman microscopy in situ with anodic polarization and MCR-ALS." Journal of Raman Spectroscopy, 43, 928-938.

Nishizawa, A., Takaya, S., Nakamura, S. and Miyagawa, T., (2013). "Influence of corrosion products on relationship between crack width and corrosion weight loss." Proceedings of the Japan Concrete Institute, 35, 1051-1056. (in Japanese)

Ohkubo, K, (2000). "Measurement of solubility of oxygen in electrolyte solution used in salt manufacturing process." Bulletin of the Society of Sea Water Science Japan, 54, 111-116. (in Japanese)

Oshikawa, W., Shinohara, T. and Motoda, S., (2003). "Estimation of chemical composition and thickness of water film of moist strong electrolyte solution." Zairyo-to-Kankyo, 52, 293-298. (in Japanese)
Qi, L. and Seki, H., (2001). "Analytical study on crack generation situation and crack width due to reinforcing steel corrosion." Doboku Gakkai Ronbunshu, 669/V-50, 161-171. (in Japanese)

Takaya, S., Nakamura, S., Yamamoto, T. and Miyagawa, T., (2013). "Influence of steel corrosion products in concrete on crack opening weight loss of corrosion." Journal of Japan Society of Civil Engineers, Ser. E2 (Materials and Concrete Structures), 69(2), 154-165. (in Japanese)

Tomashov, N. D., (1964). "Development of the electrochemical theory of metallic corrosion." Corrosion, 20(1), 7-14.

Tomashov, N. D., (1966). "Theory of corrosion and protection of metals: The science of corrosion." New York: Macmillan Inc.

Yamamoto, T., Takaya, S., Nakamura, H., Shimomura, T. and Miyagawa, T., (2018). "Preliminary assessment methodology for detailed investigation in corroded RC member using crack width due to corrosion". In: Proceedings of the 18th JSMS Symposium on Concrete Structure Scenarios, Kyoto, Japan 25-26 October 2018. Kyoto: The Society of Materials Science, Japan, 18, 143-148. (in Japanese) 